\title{
FISTULO-ENTERIC ANASTOMOSIS- PROPOSED NEW SURGICAL TECHNIQUE FOR THE MANAGEMENT OF BILIOCUTANEOUS FISTULA
}

\author{
Samir S. Deolekar1, Dnyaneshwar Mohare², Anuj Sharma33, Preeti Vijaykumaran ${ }^{4}$ \\ ${ }_{1}^{1}$ Associate Professor and Unit Head, Department of Surgery, Seth GS Medical College, Parel, Mumbai, India. \\ ${ }^{2}$ Assistant Professor, Department of Surgery, Seth GS Medical College, Parel, Mumbai, India. \\ ${ }^{3}$ Registrar, Department of Surgery, Seth GS Medical College, Parel, Mumbai, India. \\ ${ }^{4}$ Registrar, Department of Surgery, Seth GS Medical College, Parel, Mumbai, India.
}

\section{ABSTRACT}

\section{BACKGROUND}

External biliary fistula (Biliocutaneous fistula) are known to occur following trauma as well as surgery. A multidisciplinary approach including Internal Medicine, Surgery, Endoscopy and Interventional Radiology Specialists are required to manage the complex disease. Surgery is reserved for cases where expectant and endoscopic management fails. Till today the procedure of choice is hepaticojejunostomy. We propose to introduce a new technique: fistula-enteric anastomosis, which has significant advantages as compared to the standard hepaticojejunostomy procedures. This technique not only reduces the post-operative complications associated with a major procedure like Hepaticojejunostomy, but is also easier to perform not requiring highly skilled resources and expertise and has lesser post-operative morbidity.

\section{KEY WORDS}

Bile Duct, Cholecystectomy, Bile Duct Injury, Fistula, Laparoscopy, Hepaticojejunostomy.

HOW TO CITE THIS ARTICLE: Deolekar SS, Mohare D, Sharma A, et al. Fistulo-enteric anastomosis - proposed new surgical technique for the management of biliocutaneous fistula. J. Evolution Med. Dent. Sci. 2018;7(18):3639-3641, D0I: $10.14260 /$ Jemds/2018/817

\section{BACKGROUND}

Laparoscopic Cholecystectomy has emerged as a better alternative to the conventional open cholecystectomy procedure due to better cosmesis, shorter postoperative stay and lesser postoperative morbidity.[1] But this gradual shift in procedure of choice has witnessed increased incidence of Bile duct injuries. Bile duct injuries post-laparoscopic procedure were initially attributed to the learning curve of the surgeon, but still with over two decades of our experience with laparoscopic cholecystectomy the incidence of Bile duct injuries is still higher than the open cholecystectomy. ${ }^{[2]}$ External biliary fistula (Biliocutaneous fistula) are known to occur following trauma as well as surgery. A multidisciplinary approach including Internal Medicine, Surgery, Endoscopy and Interventional Radiology Specialists are required to manage the complex disease. Surgery is reserved for cases where expectant and endoscopic management fails. Till today the procedure of choice is hepaticojejunostomy. We propose to introduce a new technique: fistula-enteric anastomosis, which has significant advantages as compared to the standard hepaticojejunostomy procedures. This technique not only reduces the postoperative complications associated with a major procedure like Hepaticojejunostomy, but is also easier to perform not requiring highly skilled resources and expertise and has lesser postoperative morbidity.

Financial or Other, Competing Interest: None.

Submission 16-01-2017, Peer Review 17-02-2017,

Acceptance 23-02-2017, Published 06-08-2018.

Corresponding Author:

Dr. Anuj Sharma,

Department of General Surgery,

OPD Building, Second Floor,

Seth GS Medical College and KEM Hospital, Parel,

Mumbai, India.

E-mail:anuj9863@gmail.com

DOI: $10.14260 /$ jemds/2018/817

\section{(c) (i) $($ ) $\Theta$}

\section{Case Details}

A 45-year-female admitted with us had undergone elective open cholecystectomy in a private hospital 2 months back. On a postoperative day 2, drain (Ryle's tube) was found to be bilious. She was managed conservatively for 2 months with daily drain output of $300-500 \mathrm{~mL}$. In view of failed conservative management, she was referred to our Tertiary Health Care Centre for further management.

On admission, the patient had the mild dull aching type of right hypochondriac pain. The patient was haemodynamically stable. Abdomen was soft with healed scar of previous surgery (upper right paramedian incision). Her drain was bilious.

Blood investigation including liver function tests was within normal limits. The patient was investigated to know the site of injury and for any intra-abdominal collection. MRCP was suggestive of type $E_{2}$ bile duct injury (As per Strasberg classification). (Figure 1) With no significant free fluid in the abdominal cavity and only small bilioma, PTBD was inserted into the right hepatic duct for temporary diversion of bile.

The patient was prepared and electively taken up for surgery after 1 week of admission with us. Intraoperatively, there was no significant free fluid in the abdominal cavity. Sub-hepatic space was frozen with bowel adhesions. A bilocutaneous fistula was identified (Outlining the drain in situ) (Figure 2). The drain was removed. The fistula was disconnected from the abdominal wall and traced proximally to get the adequate length for anastomosis without any tension. Fistulous tract was well-vascularised with no luminal narrowing (As confirmed with a cannula). The fistulous tract was anastomosed with a jejunal segment one foot from duodenojejunal flexure (Roux-en-Y anastomosis) with single layer interrupted 3-0 PDS sutures. PTBD was left in situ.

Postoperative period was uneventful. The patient was started on orals on postoperative day 4. Morrison's drain 
showed no bile drainage and was removed on day 6 . All blood investigations (including liver function tests) were within normal limits. PTBD was clamped. PTBD gram did on a postoperative day 10 showed the free flow of bile in the jejunum with no leak and so it was removed.

The patient was discharged and followed up for 1 year. The patient was asymptomatic, non-icteric and liver function tests were within normal limits. On followup MRCP was done 2 months after surgery, which showed almost complete resolution of bilioma and non-dilated biliary system (Figure 3). Liver function tests were normal.

\section{DISCUSSION}

External biliary fistula (Biliocutaneous fistula) can occur due to traumatic or surgical injury to the liver or hepatobiliary tract.[3] Though laparoscopic cholecystectomy gives better cosmetic results than open cholecystectomy, the incidence of injury to the bile duct is marginally more with laparoscopic as compared to open cholecystectomy.[2] The injury generally results from imprecise dissection and inadequate demonstration of the biliary structures.[4] Such fistula has also been reported after liver biopsy and percutaneous radiofrequency ablation of hepatocellular carcinoma.[5]

In our case, this patient had developed a biliocutaneous fistula secondary to bile duct injury during open cholecystectomy.

Chronic external biliary fistulae can lead to complications like fat-soluble vitamin deficiency, steatorrhea, jaundice, cholangitis (with obstructed fistula) or skin erosions.

ERCP is a useful diagnostic and therapeutic tool when the continuity of the extrahepatic biliary system has not been disrupted. Magnetic Resonance Cholangiopancreatography (MRCP) is a non-invasive technique for outlining both the intro- and extra-hepatic biliary tree, which can describe the anatomy of the fistula better than an ERCP.[6]

Biliocutaneous fistula following low-grade bile duct injury, mostly resolves spontaneously with a conservative line of management, usually following endoscopic intervention. Spontaneous closure can occur after endoscopic procedures like sphincterotomy, stenting or no biliary drainage (due to decreased pressure in the biliary system).[7,8]

Surgery is planned in cases of failed conservative management. Surgery of choice in those circumstances is Roux-en-Y hepaticojejunostomy.[9] However, there are known complications of hepaticojejunostomy like bile leak, strictures and recurrent episodes of cholangitis.[10]

However, in a presence of an epithelialised fistulous tract as described in our study, the fistula can be used as a conduit for anastomosing biliary system with intestinal tract where endoscopic technique is not possible or failed and where surgery is planned. This is our second such experience in managing external biliary fistula. Previously a 40-year-male patient presented to us with external biliary fistula following open cholecystectomy. The patient had undergone pancreaticojejunostomy for chronic pancreatitis in the past following which he developed CBD stricture which leads to fistula following cholecystectomy. A bilocutaneous fistula was identified and a fistula-duodenal anastomosis was done. Postoperatively, patient recovered well and was followed up for 6 months with no complications and normal liver function tests. This case was reported and eventually got published in the Internet Journal of Surgery, 2012, volume 28, number 2.[11]

\section{Advantages of Fistulo-Enteric Anastomosis}

1. It is suitable for all types of bile duct injuries. Surgical approach need not change with the type of injury, even in cases of high biliary injuries requiring high bilioenteric anastomosis or even liver transplantation in rare instances.

2. Complication like stricture associated with hepaticojejunostomy would be low. Hepaticojejunostomy strictures eventually lead to recurrent cholangitis and may require re-exploration. The cause for stricture is ischaemic fibrosis and smaller diameter of bile duct at the site of the anastomosis. But if the fistulous tract is used as a conduit, this complication would be probably low or nil as tract is well vascularised due to omental covering in most cases and is of good diameter. Hence, incidences of redo surgery will be less.

3. The surgery is less invasive as no approach to the porta is required and therefore there will be minimal blood loss.

4. It can be managed by a general surgeon and does not require a specialist, hepatobiliary surgeon.

5. Cosmetically better due to easy accessibility of fistulous tract via subcostal incisions and bigger incisions as for hepaticojejunostomy are not required.

\section{CONCLUSION}

Fistulo-enteric approach, thus we find to be a promising surgery in patients presenting with biliocutaneous fistula following complex bile duct injuries. It is an operative technique with significant advantages in all cases of hepatobiliary injuries with lesser morbidity compared to standard hepaticojejunostomy procedure.

\section{REFERENCES}

[1] McMahon AJ, Russell IT, Baxter JN, et al. Laparoscopic versus minilaparotomy cholecystectomy: a randomised trial. Lancet 1994;343(8890):135-8.

[2] Mercado MA, Chan C, Orozco H, et al. Acute bile duct injury. Surg Endosc 2003;17(9):1351-5.

[3] Kern E, Schneider H. Strikturen and fisteln tier gallenwege. In: Kühn HA, Wernze H, (eds.) Klinische hepatologie. Thieme, Stuttgart 1979:784-9.

[4] Gilbo N, Mirabella S, Strignano P, et al. External biliary fistula in orthotopic liver transplantation. Transplant Proc 2009;41(4):1316-8.

[5] Hatzidakis A, Petrakis I, Mantatzis M, et al. Biliocutaneous fistula formation after percutaneous liver mass biopsy: embolization of the tract with a gelatin matrix. Int Surg 2006;91(6):341-4.

[6] Musher DR, Gouge T. Cutaneous bile fistula treated with ERCP-placed large diameter stent. Am Surg 1989;55(11):653-5.

[7] Sharma AK. External biliary fistula. Trop Gastroenterol 2001;22(3):163-8.

[8] Burmeister W, Köppen MO, Wurbs D, et al. Treatment of a biliocutaneous fistula by endoscopic insertion of a nasobiliary tube. GIE 1985;31(4):279-81. 
[9] O’Rahilly S, Duignan JP, Lennon JR, et al. Successful treatment of a post-operative external biliary fistula by endoscopic papillotomy. Endoscopy 1983;15(2):68-9.

[10] Zen M, Dintsman M. External biliary-pancreatic fistulas. Int Sur 1977;62(3):175-8.

[11] Mate A, Tapase M, Deolekar S, et al. Management of biliocutaneous fistula: fistula-duodenal anastomosis. Internet journal of surgery 2012;28(2):1-5. 